Psychological Medicine, 1988, 18, 15-20

Printed in Great Britain

EDITORIAL

\title{
Research in stress, coping, and health: theoretical and methodological issues ${ }^{1}$
}

In recent years, research interest in stress, coping, and health has grown considerably. This growing interest has produced a substantial body of literature and, concurrently, an extensive variety of theoretical and methodological approaches. While this research activity has significantly increased our understanding of the impacts of stress and coping on health, it also has produced considerable confusion and disagreement concerning the exact meaning of stress, coping, and health, the causal relationships among these constructs, and the appropriate methodological approaches for the assessment of these constructs and their interrelationships.

The purpose of this editorial is to discuss current theoretical and methodological approaches to the study of stress, coping, and health, to identify problems associated with these approaches, and to suggest tentative solutions to these problems. This discussion will take the form of a general overview rather than a detailed critique of specific theoretical or methodological approaches. By doing this, we will identify issues which are relevant to a broad audience employing a variety of research techniques. For detailed discussion of specific approaches, we will direct the reader to available literature (for general discussions, see Kessler, 1983; Lazarus \& Folkman, 1984; for a recent volume covering a variety of issues, see Kasl \& Cooper, 1987).

To structure this paper, we will discuss issues which primarily concern stress, coping and health in separate sections. We emphasize that this is done for convenience of presentation rather than to suggest independence of the issues addressed. As the following discussion will illustrate, many issues are highly interrelated and, as a result, are relevant whether the research worker's specific focus is stress, coping, or health.

\section{STRESS: THEORETICAL AND METHODOLOGICAL ISSUES}

\section{The confounding of stress, coping, and well-being}

In stress research the concepts of stress, coping, and well-being are frequently confounded. This confounding is exemplified in life events research, where some 'stressful' life events may also be construed as an inability to cope (e.g. divorce) or a symptom of well-being (e.g. personal illness) (Dohrenwend et al. 1984; see also Lazarus et al. 1985, Dohrenwend \& Shrout, 1985, and the ensuing debate in the American Psychologist 41, pp.713-719). Similarly, measures of role stress (e.g. ambiguity, conflict, overload) and responses to role stress (strain, distress), are often so similar that they may actually tap the same construct (Kasl, 1978). Furthermore, some definitions of stress, such as those which describe stress as a situation where demands exceed abilities (French et al. 1974; Sells, 1970), confound stress with the inability to cope. To advance our understanding of the relationships among stress, coping, and health, we must derive specific and conceptually distinct definitions and operations of these constructs. At least, we should separately assess individuals' perceptions of events (a simple reporting of 'what is'), the standards by which they evaluate these events (values, desires, expectations, abilities, etc.), individuals' appraisal (i.e. perceptions relative to standards), health-related outcomes, and coping efforts directed toward altering perceptions, standards, and/or health-related outcomes.

' Address for correspondence: Professor C. L. Cooper, Department of Management Sciences, University of Manchester Institute of Science and Technology, PO Box 88, Manchester M60 IQD. 


\section{Individual differences in the evaluation of stressors}

Stress is often described in terms of specific life events (Holmes \& Rahe, 1967; Parker \& DeCotiis, 1983). This approach rests on the normative assumption that the degree of stress associated with these events is consistent across individuals, thereby ignoring individual differences in the appraisal of life events and the process by which the occurrence of life events is translated into health outcomes (Lazarus, 1966; Lazarus \& Folkman, 1984). Research has shown that individual differences in the appraisal of life events influence the amount of stress associated with these events and their impacts on health, indicating that inattention to these individual differences conceals important processes (Cooper et al. 1985; for an excellent review, see Thoits, 1983). To clarify our understanding of the impact of life events on health, we must include the individual's appraisal of these events as a critical intervening variable. This may be accomplished by asking individuals to provide their own evaluation of each life event relative to some internal standard, such as values, desires, expectations, abilities, or whatever standard is important to the individual and consistent with the research worker's theoretical focus.

\section{Sources of stress other than major life events}

Many investigators describe stress in terms of major life events, using the Holmes \& Rahe (1967) Schedule of Recent Life Events, or one of its variants. While this approach provides a reasonable assessment of the occurrence of an array of major life events, it fails to capture additional sources of stress in the individual's psychosocial environment which are not associated with the occurrence of major life events. One additional source of stress involves the occurrence of chronic minor life events (i.e. 'daily hassles'). Recent research suggests that these events constitute a significant but often overlooked source of stress (DeLongis et al. 1982; Kanner et al. 1981; Lazarus, 1984; Monroe, 1983). A second additional source of stress involves social information, i.e. information provided by others in the individual's psychosocial environment. This may be contrasted with social support, which casts information provided by others as a potential coping resource rather than as a source of stress (Cohen \& McKay, 1984). While the role of social information as a source of stress has not been addressed, research in the area of job satisfaction indicates that social information may influence individuals' perceptions of and responses to their environment (Blau \& Katerberg, 1982; Salancik \& Pfeffer, 1978; Shaw, 1980). Stress r search would benefit by evaluating the contribution of major life events, minor life events, and social information to the overall level of stress experienced by individuals.

\section{Stress produced by the individual}

Most approaches to the study of stress assume, either implicitly or explicitly, that stress originates from some situation or event in the individual's environment. This approach ignores sources of stress which originate from within the individual. One example of this type of stress is worry associated with situations or events which have yet to occur, or which may never occur at all (Caplan, 1983; Caplan et al. 1985; Spacapan \& Cohen, 1983). Another example involves 'imagined' sources of stress, such as suspicions concerning a spouse's fidelity or doubts concerning others' appraisal of oneself. A third example involves sources of stress created by an individual's own behaviour. For example, the sense of urgency common among Type-A individuals may prompt them to compress an increasing number of activities into a fixed amount of time, leading to overload and stress. As these examples illustrate, several important sources of stress originate from within the individual and become manifest in their cognitive construction of reality or in their behaviours which, in turn, create stress. A comprehensive assessment of stress demands attention to these potentially important but often neglected stressors. 


\section{COPING: THEORETICAL AND METHODOLOGICAL ISSUES}

\section{Coping at multiple stages in the stress process}

In models of the stress and coping process, coping is typically positioned between the individual's appraisal of stress and health-related outcomes. That is, individuals who appraise a situation or event as stressful engage in coping activities, which either have a direct effect on health, or moderate the relationship between appraised stress and health (Wheaton, 1985). While this approach captures important mechanisms by which coping may affect health, it ignores other viable pathways. For instance, coping may intervene prior to the appraisal of stress, thereby preventing the appraisal of a situation or event as stressful. This form of coping is evidenced in some forms of bias and distortion found in self-report data, which some research workers have labelled as measurement error. However, these biases and distortions may be evidence of palliative coping processes (Lazarus \& Launier, 1978); an explicit study of these biases and distortions as a form of coping would improve our understanding of the coping process (Kasl \& Cooper, 1987). Alternately, coping may occur after deleterious health outcomes have been realized. For example, an executive under stress may refrain from engaging in coping activities until after the manifestation of coronary heart disease. These examples illustrate the multiple stages in the stress process in which coping may occur. Future models of stress and coping should include these multiple pathways and evaluate their relative contribution to the reduction of stress and the improvement of health.

\section{The stress of coping}

Current stress and coping research focuses primarily on the stress-reducing effects of coping. While coping may, indeed, reduce stress, the implementation of a coping strategy may also serve as a source of stress (Cohen et al. 1986). For example, some coping strategies may be inherently aversive to the individual, such that their implementation may produce stress and damage health. Similarly, the failure of a coping strategy per se may function as a source of stress, particularly when the individual is ego-involved in the success of the coping strategy and wants it to succeed for its own sake. Alternatively, the process of deciding which coping strategy to implement may tax an individual's cognitive abilities, producing stress. Further, the implementation of a coping strategy may deplete adaptive energies, making the individual vulnerable to additional stressful encounters (Cohen, 1980; Dubos, 1968; Selye, 1956). As depicted by these examples, the coping process itself may serve as an important source of stress, and attention to the stress of coping will improve our overall understanding of the impact of coping on health.

\section{The determinants of coping}

In research on coping, investigators focus primarily on the effects of coping on stress and health, paying little attention to determinants of coping. As a result, we know little about the process by which individuals select and implement coping strategies. Several possible processes may be identified. For example, the individual may carefully evaluate the potential costs and benefits of available coping strategies and implement one which is evaluated as most likely to reduce stress and improve health (Janis, 1974; Janis \& Mann, 1977; Spivack et al. 1976). In some cases, this process will result in the selection and implementation of a viable coping strategy, while in other cases the costs of all available coping strategies may exceed their benefits, prompting the individual to abstain from coping. Though the research worker may consider such abstinence puzzling and maladaptive, it may make perfect sense to the individual, given the perceived costs and benefits of the available coping strategies. While individuals may employ this apparently rational decision-making process in some cases, in other cases they may employ nonrational processes, relying on heuristics, biases, and habits in the selection and implementation of coping strategies (cf. Behling et al. 1975; Staw \& Ross, 1985; Tversky \& Kahneman, 1974; Wahba \& House, 1974). Given the deleterious effects of stress on decision-making processes (Cohen, 1980), it is likely that these nonrational processes are often used. Future research should attempt to identify the various processes by which individuals 
select and implement coping strategies, the factors relevant to these processes, and the conditions under which a given process is used.

\section{The impact of coping on stress}

Traditional models of stress, coping, and health are recursive, positing a unidirectional causal flow. In general, these models pose factors in the environment (i.e. stressors) as antecedent variables, individual appraisal of these stressors as a mediating variable, coping behaviours and resources as either mediating or moderating variables, and health outcomes as criterion variables. Though intuitively appealing, this approach ignores the mechanisms by which coping strategies affect (or fail to affect) the causes of stress. Instead, research workers usually examine the direct effects of coping on health and/or the moderating effects of coping on the relationship between stress and health, without assessing the relationship between coping and the individual and environmental factors which caused stress in the first place (Billings \& Moos, 1981, 1984; Folkman \& Lazarus, 1985; Pearlin \& Schooler, 1978). If our models adequately identify the determinants of stress, we should be able to determine the effectiveness of coping strategies by examining the degree to which these strategies affect the determinants of stress. This proposition may be tested by deriving models which include feedback mechanisms linking coping strategies to the determinants of stress and by empirically evaluating the effects of coping on the determinants of stress (Cummings \& Cooper, 1979; McGrath, 1976).

\section{HEALTH: THEORETICAL AND METHODOLOGICAL ISSUES}

\section{The interrelationships among health outcomes}

Investigations of the impact of stress and coping on health typically focus on a single health outcome or, if multiple outcomes are included, examine these outcomes in a piecemeal fashion. This approach ignores potential interrelationships among indices of mental and physical health. The detection of these interrelationships is important for two reasons. First, multiple health indices may reflect a smaller number of underlying constructs. For example, phasic changes in cardiovascular and electrodermal activity may indicate changes in general physiological arousal rather than distinct physiological outcomes. Similarly, multiple measures of mood may simply reflect positive and negative affect rather than separate psychological dimensions (Gotlib \& Meyer, 1986). Secondly, interrelationships among health indices may reflect causal relationships among these variables. For example, the impact of stress on physical health may be mediated by mental health, such that stress produces depression, anxiety, etc., which in turn affect physiological variables. In addition, physiological (or psychological) variables may be interdependent, as exemplified by the impact of catecholamines and lipoproteins on cardiovascular health. Our understanding of the impact of stress and coping on health would be considerably advanced by viewing indices of mental and physical health as an interrelated set of outcomes, rather than as separate and independent criteria, and by mapping out the causal and correlational relationships among these outcomes.

\section{Positive health outcomes}

The greater part of stress and coping research focuses on the deleterious impacts of these variables on health. This bias is reflected in the measures of mental and physical health used in most studies, which primarily focus on illness and dysfunction. By focusing specifically on mental and physical illness and dysfunction, we ignore the possibility that certain aspects of the stress and coping process may actually improve health. For example, life events which are evaluated as positive may buffer the individual from experienced stress (Cohen \& Hoberman, 1983). Furthermore, anecdotal evidence suggests that, rather than merely buffering the negative effects of stress, positive psychological states may produce positive physiological outcomes (Cousins, 1976). Similarly, some research workers indicate that individuals who successfully cope with demanding situations may experience physiological growth and regeneration (Karasek et al. 1982). The prospect that the appraisal of situations or events as positive, or that successfully coping with stress may improve health, is an 
intriguing possibility, and future research should include measures which allow for the detection of these positive health outcomes.

\section{The timing and manifestation of health outcomes}

In stress research, the measurement of health outcomes generally occurs over a very limited number of occasions. Because of this, we know very little about the timing and manifestation of health outcomes. For example, some responses to stress may develop, peak and subside over a period of time, while others may asymptotically approach a maximum level as stress persists. This intensification and diminution of health outcomes over time may be a function of the nature of the stressor, the adaptability of the individual, the health outcome under consideration, or all three. Depending on how we synchronize our health measures with the timing and manifestation of health outcomes, we may fail or succeed to detect the impact of stress and coping on health. Perhaps the low correlations between stress and health found in many studies (often less than 0.30 ) are partially attributable to the measurement of health outcomes over an inappropriate time interval. Future research should measure health outcomes over as many occasions as possible, thereby providing information concerning the development and subsidence of health outcomes over time (Kessler, 1987).

\section{CONCLUSION}

In this editorial, we have identified several problems associated with current approaches to the study of stress, coping, and health, and have suggested tentative solutions to these problems. Our intention was not to critique specific theoretical or methodological approaches. Instead, we raised general issues which cut across a variety of approaches, thereby appealing to a wider audience. It is hoped that, by considering the issues we have raised, research workers will avoid potential problems and explore new possibilities concerning the interrelationships between stress, coping, and health.

JEFFREY R. EDWARDS AND CARY L. COOPER

\section{REFERENCES}

Behling, O., Schriesheim, C \& Tolliver, J. (1975). Alternatives to expectancy theories for work motivation. Decision Sciences 6 , 449461

Billings, A. G. \& Moos, R. H. (1981). The role of coping responses and social resources in attenuating the stress of life events. Journal of Behavioural Medicine 4, 139-157.

Billings, A. G. \& Moos, R. H. (1984). Coping, stress, and social resources among adults with unipolar depression. Journal of Personality and Social Psychology 46, 877-891.

Blau, G. J. \& Katerberg, R (1982). Toward enhancing research with the social information processing approach to job design. Academy of Management Review' 7, 543-550

Caplan, R. D. (1983). Person-environment fit: past, present, and future. In Stress Research (ed. C. L. Cooper), pp. 35-78. Wiley. New York.

Caplan, R. D., Tripathi, R. C. \& Naidu, R. K. (1985). Subjective past, present and future fit. effects on anxiety, depression, and other indicators of well-being. Journal of Personality and Social Psychology 8, 180-197.

Cohen, S. (1980). After-effects of stress on human performance and social behaviour: a review of research and theory. Psychological Bulletin 88, 82-108.

Cohen, S. \& Hoberman, H. (1983). Positive events and social supports as buffers of life change stress: maxımizing the prediction of health outcome. Journal of Applied Social Psychology 13, 99125.

Cohen, S. \& McKay, G. (1984). Social support, stress, and the buffering hypothesis: a theoretical analysis. Handbook of Psychology and Health, (Vol. 4) (ed. A. Baum, J. E. Singer and S. E. Taylor), pp. 253-267. Erlbaum: Hillsdale, N. J.
Cohen, S., Evans, G W., Stokols, D. \& Krantz, D. (1986). Behavior Health and Environmental Stress. Plenum: New' York.

Cooper, C. L.. Cooper. R. \& Faragher, B (1985) Stress and life events methodology. Stress Medicine 1, 287-289.

Cousins, N. (1976). Anatomy of an illness (as perceived by the patient). New England Journal of Medicine 295, 1485-1463.

Cummings, T. G. \& Cooper, C. L. (1979). A cybernetic framework for studying occupational stress. Human Relations 32, 395-418.

DeLongis, A., Coyne, J. C, Dakof, G., Folkman, S. \& Lazarus, R. S. (1982). Relationshıp of daily hassles, uplifts, and major life events to health status. Health Psychology 1, 119-136.

Dohrenwend, B. P. \& Shrout, P E (1985). 'Hassles' in the conceptualization and measurement of life stress variables. American Psychologist 40, 780-785.

Dohrenwend, B. S., Dohrenwend, B P., Dodson, M. \& Shrout, P. E. (1984). Symptoms, hassles, social supports, and life events: the problem of confounded measures. Journal of Almormal Psychology 93, 222-230.

Dubos, R. (1968). Environmental determınants of human life. In Biology and Behavior: Environmental Influences. (ed. D. C. Glass), Rockefeller University Press/Russel Sage Foundation. New York.

Folkman, S. \& Lazarus, R. S. (1985). If it changes, it must be a process: a study of emotion and coping during three stages of a college examination. Journal of Personality and Social Psychology 48, 150170.

French, J. R. P., Jr, Rodgers, W. L. \& Cobb, S. (1974). Adjustment as person-environment fit. In Coping and Adaptation (ed. G. Coelho, D. Hamburg, and J. Adams), pp. 316-333. Basic Books: New York. 
Gotlib, I. H. \& Meyer, J. P. (1986) Factor analysis of the Multiple Affect Adjective Check List: a separation of posituve and negative affect. Journal of Personality and Social Psychology 50, 11611165

Holmes, T. H. \& Rahe, R. H. (1967). Social readjustment ratıng scales. Journal of Psychosomattc Research 11, 213-218

Janis, I. L. (1974). Vigilance and decision-making in personal crises. In Coping and Adaptation (ed. G. Coelho, D. A. Hamburg, and J. E. Adams), pp. 139-175. Basic Books: New York.

Janis, I. L. \& Mann, L. (1977). Decision Making The Free Press: New York.

Kanner, A. D., Coyne, J. C., Schaefer, C. \& Lazarus, R. S. (1981). Comparison of two modes of stress measurement: Daily hassles and uplifts versus major life events. Journal of Behavoral Medicine $4,1-40$

Karasek, R. A., Jr., Russell, R. S \& Theorell, T. (1982). Physiology of stress and regeneration in job related cardiovascular illness. Journal of Human Siress 8, 29-42.

Kasl, S. V. (1978). Epidemiological contributions to the study of work stress. In Stress at Work (ed. C L Cooper and R Payne), pp. 3-48. Wiley. New York.

Kasl, S V. \& Cooper, C. L. (Eds.) (1987). Stress and Health: Issues in Research Methodology. John Wiley: Chichester

Kessler, R. (1983). Methodological issues in the st udy of psychological stress. In Psychological Stress: Trends in Theory and Research (ed. H. Kaplan), pp. 267-341. Academic Press: New York.

Kessler, R. C. (1987). The interplay of research design strategies and data analysis procedures in evaluating the effects of stress on health. In Stress and Health: Issues in Research Methodology (ed. S. V. Kasl and C. L. Cooper), pp. 113-140. John Wiley: Chichester.

Lazarus, R. S. (1966). Psychological Stress and the Coping Process. McGraw-Hill: New York.

Lazarus, R. S (1984). Puzzles in the study of daily hassles. Journal of Behavioral Medicine 7, 375-389.

Lazarus, R. S. \& Folkman, S. (1984). Stress, Coping, and Adaptation. Springer: New York

Lazarus, R. S. \& Launer, R. (1978). Stress-related transactions between person and environment. In Perspective in Interactional Psychology (ed. L. A. Pervin and M. Lewis), pp. 287-327. Plenum: New York.
Lazarus, R. S., DeLongis, A., Folkman, S. \& Gruen, R. (1985). Stress and adaptational outcomes: the problem of confounded measures American Psychologist 40, 770-779.

McGrath, J. E. (1976). Stress and behavior in organizations. In Handbook of Industrial and Organizational Psychology (ed. M. Dunnette), pp. 1351-1395. Rand McNally: Chicago.

Monroe, S. M. (1983). Major and minor life events as predictors of psychological distress: further issues and findings. Journal of Behavioral Medicine 6, 189-205.

Parker, J. F. \& DeCotiis, T. A. (1983). Organizational determınants of job stress. Organizational Behavior and Human Performance 32, 160-177.

Pearlin, L. I. \& Schooler, C. (1978). The structure of coping. Journal of Health and Social Behavior 19, 2-21.

Salancik, G. R. \& Pfeffer, J. (1978). A social information processing approach to job attitudes and task design. Administrative Science Quarterly 23, 224-253.

Sells, S. B. (1970). On the nature of stress. In Social and Psychological Factors in Stress. (ed. J. E. McGrath), Holt: New York.

Selye, H. (1956). The Stress of Life. McGraw-Hill - New York

Shaw, J. B. (1980). An information-processing approach to the study of job design. Academy of Management Review 5, 41-48.

Spacapan, S. \& Cohen, S. (1983) Effects and aftereffects of stressor expectations. Journal of Personality and Social Psychology 45, 1243-1254.

Spivack, G., Platt, J. J. \& Shure, M. B. (1976). The Problem-solving Approach to Adjustment. Jossey-Bass: San Francisco.

Staw, B. M. \& Ross, J. (1985). Stability in the midst of change: a dispositional approach to job attitudes. Journal of Applied Psychology 70, 469-480

Thoits, P. A. (1983). Life events and psychological distress. In Psychological Stress: Trends in Theory and Research (ed. H. B. Kaplan), pp. 33-103. Academic Press: New York.

Tversky, A. \& Kahneman, D. (1974). Judgement under uncertainty heuristics and biases Science 185, 1124-1131.

Wahba, M. A. \& House, R. J. (1974). Expectancy theory in work and motivation: some logical and methodological issues. Human Relations 27, 121-147.

Wheaton, B. (1985). Models for the stress-buffering functions of coping resources. Journal of Health and Social Behavior 26, 352364. 